and V. L. Karpov. The general standard is high, and the topics discussed cover most fields which occupy the minds of radiation chemists at present. The translations are excellent, and, although some time has elapsed since the papers were read, they provide a source of information on Russian work in this field which will be very valuable. Unfortunately, the language barrier has been surmounted only by the introduction of an equally formidable price barrier. G. Porter

\section{Sourcebook on Atomic Energy}

By Dr. Samuel Glasstone. Second edition. Pp. $\mathrm{v}+641$. (Princeton, N.J. : D. Van Nostrand Company, Inc.; London: D. Van Nostrand Company, Ltd., 1958.) $34 s$.

$\mathrm{D}$ R. GLASSTONE'S book, prepared under the direction of the Technical Information Service of the United States Atomic Energy Commission, has been available for eight years and a new edition is therefore timely.

The book seems to have been re-set and is on whiter paper; but it has not lost its excellence as a source of scientific and historical information on nuclear energy. Though much of the text has been retained, it has been brought up to date in several respects: the anti-proton and anti-neutron are included, and more is reported on mesons. Unfortunately, the book just missed the complete declassification of thermonuclear research for the production of nuclear energy, though some of the information which was declassified at the time the book was written has been included. A new and very useful chapter is devoted to reactors; it is of the same high standard as the rest of the book, although the account of the considerable British power achievements seems rather short in comparison with their pioneering importance.

Though it is essentially a physics book, some data on the economics of nuclear energy would be valuable in a next edition.

This new edition stands in the forefront of books of its kind; it provides the 'intelligent layman's guide to nuclear energy'.

E. BRETSCHER

\section{Introduction to Meteorology}

By Prof. Sverre Petterssen. Second edition. Pp. ix +327 . (London: MeGraw-Hill Publishing Company, Ltd., 1958.) 52s. $6 d$.

$\mathrm{O}$ OR the second edition of a book written seventeen years ago Prof. S. Petterssen has gone to much trouble to provide a complete revision addressed to "students who are considering meteorology as a profession" and also to "students in geography, agriculture, aviation and various industries. . . .".

It is a serious and substantial book surveying weather science from instruments and observations through the basic physical processes to synoptic meteorology and world climate, and yet assuming for the reader a previous knowledge of mathematics and physics at first-year grammar school level. What can be done on this basis is quite remarkable provided that scientific explanation is restricted to the qualitative application of physical principles with an occasional simple formula, and, while it may be doubted whether specialist students of meteorology should begin in this way, there is no doubt of the demand for instructional text-books for the use of those much more numerous students whose interests lie primarily in other fields. The geographers, agriculturists, airmen and the like, who are not only interested in weather science but also may very well need to pass examinations in the subject, may count themselves fortunate in that one of our most eminent professors, now president of the American Meteorological Society, has made the effort to write in simple scientific language yet without any suggestion of writing down.

The book is indeed serious, for the author only twice allows himself a frivolous phrase. It is substantial and up to date although a little surprising in that so little is made of those parts of the subject to which the author has himself contributed so much : threedimensional dynamical and synoptic meteorology. Possibly what one knows the best seems the least adapted to simple treatment. It is also not impossible to pick a few holes in the fabric. Thus I doubt if a small droplet has a high saturation vapour pressure because it resists the advances of vapour molecules in the air (p. 62); the statement that "normally the mixing ratio will increase from the ground upwards" (p. 84) is of course a slip ; that "only a small part" of the solar energy is absorbed in the atmosphere and "the bulk is absorbed at the earth's surface" (p. 88) is an exaggeration of a ratio near $1: 2$; "if the oceans were still there would be little difference between the heat exchanges over oceans and over continents" (p. 95) is a remarkable assertion.

But criticisms of this trivial kind are the only ones which can be levelled against what is a reliable and informative introduction to the study of weather and climate suitable for the non-specialist.

\section{R. C. Sutcliffe}

The Science of Photography

By Dr. H. Baines. Pp. 319. (London: Fountain Press, 1958.) 38s. 6d.

LTHOUGH Dr. H. Baines has written mainly $A$ for the non-scientist, any reader having little knowledge of the scientific background of photography will find that this book provides a good introduction to the facts and theories underlying all branches of the subject. The very wide field covered includes chapters on history, optics, the chemistry and physics of the emulsion, its preparation, characteristics and processing, colour photography, scientific and technical applications, etc.

This is a very readable book, which bridges the gap between popular articles, sometimes unreliable, on photographic theory and authoritative works unsuitable for the average photographer. C. O. HARveY

\section{Introduction to the Theory of Determinants and Matrices}

By Edward T. Browne. Pp. xi +270 . (Chapel Hill, N.C. : University of North Carolina Press ; London : Oxford University Press, 1958.) 60s, net.

THIS is a good book, well written and well printed. It covers the theory of matrices, including their applications to algebraic forms ; and it covers that theory carefully and thoroughly. A novice reading it may find the going heavy, but the development, though sometimes severe, is logical, clear, and fully stated.

The book is aimed primarily at an American audience and "the text is intended for seniors or first year graduate students". In the author's view there is enough material for two semesters work. It would be a stiff course for the novice. 